$10 \mid 2006$

Varia

\title{
Saint-Quentin (Aisne), crypte de la collégiale
}

\section{Christian Sapin}

\section{(2) OpenEdition}

\section{Journals}

\section{Édition électronique}

URL : https://journals.openedition.org/cem/440

DOI : $10.4000 /$ cem.440

ISSN : 1954-3093

Éditeur

Centre d'études médiévales Saint-Germain d'Auxerre

Édition imprimée

Date de publication : 15 août 2006

ISSN : 1623-5770

\section{Référence électronique}

Christian Sapin, "Saint-Quentin (Aisne), crypte de la collégiale », Bulletin du centre d'études médiévales d'Auxerre | BUCEMA [En ligne], 10 | 2006, mis en ligne le 08 septembre 2006, consulté le 22 septembre 2022. URL : http://journals.openedition.org/cem/440 ; DOI : https://doi.org/10.4000/cem.440

Ce document a été généré automatiquement le 22 septembre 2022.

\section{(c) (i) (2)(2)}

Creative Commons - Attribution - Pas d'Utilisation Commerciale - Partage dans les Mêmes Conditions 4.0 International - CC BY-NC-SA 4.0

https://creativecommons.org/licenses/by-nc-sa/4.0/ 


\section{Saint-Quentin (Aisne), crypte de la collégiale}

Christian Sapin 
1 A la suite des nombreuses interrogations soulevées par un premier examen du site en 2004, il est apparu nécessaire de réaliser au moins une seconde campagne d'investigation dans la crypte archéologique ( $\mathrm{XIX}^{\mathrm{e}}-\mathrm{XX}^{\mathrm{e}}$ siècles) et dans la crypte historique (XIII $-\mathrm{XX}{ }^{\mathrm{e}}$ siècles). Cette campagne avait l'objectif de compléter les relevés des anciennes stratigraphies, des structures découvertes anciennement et de vérifier par l'enlèvement des remblais modernes la chronologie relative de la zone occidentale. Cette attention devait permettre d'attendre les données fournies pour la datation par les analyses en ${ }^{14} \mathrm{C}$ des charbons de bois contenus dans les mortiers de différents horizons de construction. Il en résulte dans la partie ouest la présence (vue mais non étudiée par nos prédécesseurs) de structures maçonnées en très grand appareil, de remploi aux abords de la grande dalle de marbre noire. Le mobilier résiduel dans la couche de nettoyage confirme une présence antique avec de la céramique des $\mathrm{I}^{\mathrm{er}}-\mathrm{III}{ }^{\mathrm{e}}$ siècles mais également de l'Antiquité tardive. Les nouvelles datations de quelques charbons de bois dans les sols de tuileau pour le $\mathrm{VII}^{\mathrm{e}}$ siècle et la présence de sépultures en sarcophages pour les $\mathrm{VI}^{\mathrm{e}}$-VII ${ }^{\mathrm{e}}$ siècles conduisent désormais à accepter l'hypothèse d'une continuité d'occupation ${ }^{1}$.

2 À l'est, nous avons poursuivi l'enlèvement des remblais modernes contre les départs de l'abside et avons commencé la fouille des quelques $\mathrm{cm}^{2}$ de niveau en place. Ces travaux ont révélé d'autres maçonneries nord-sud qui contredisent en partie l'hypothèse d'une simple crypte annulaire. Au haut Moyen Âge, l'existence d'un premier chevet de plan carré est probable, mais le processus de transformation de cette partie du chevet l'insertion d'une crypte à l'époque carolingienne, pour placer les tombeaux de saint Quentin, puis plus tard de saint Cassien et de saint Victorice- est plus complexe qu'on ne l'imagine. Nous rappelons que les travaux du XIX ${ }^{e}$ siècle et la destruction de 1917 ont considérablement réduit les indices de la construction d'origine encore en place. Nous devons poursuivre l'examen des vestiges (le mur de l'abside semble indiquer au moins deux ou trois états dans sa réalisation) et la fouille des zones non touchées.

\section{NOTES DE FIN}

1. Bulletin du Centre d'études médiévales d'Auxerre, Études \& travaux, CEM 9

(2004-2005), p. 43-44.

\section{INDEX}

Mots-clés : collégiale, crypte

Index géographique : France/Saint-Quentin 